about the perpendicular bisecting plane.

When an extra $\mathrm{CO}$ molecule is added to $\mathrm{CuCO}$ and $\mathrm{FeCO}$, the topographical images displayed symmetry. However, the plane containing the $\mathrm{Fe}(\mathrm{CO})_{2}$ molecule is orthogonal to the plane containing the $\mathrm{Cu}(\mathrm{CO})_{2}$ molecule.

Detailed information of chemical bonding was provided by single-molecule vibrational spectroscopy using the STM. Different stretched and hindered rotation energies of $\mathrm{CO}$ molecules were obtained by using different $\mathrm{C}$ and $\mathrm{O}$ isotopes. This way, a basis of $\mathrm{Cu} / \mathrm{Fe}$ comparison was established.

The $\mathrm{Cu} / \mathrm{Fe}$ carbonyl molecules may be deconstructed the same way they are made. Deconstruction, however, is a less controlled procedure. In the case of $\mathrm{Cu}(\mathrm{CO})_{2}$, the tip picked up one $\mathrm{CO}$ molecule (at $100 \mathrm{nA}$ and $250 \mathrm{mV}$ ) and dropped it off. When the tip returned for the second $\mathrm{CO}$ molecule, however (at $100 \mathrm{nA}$ and $500 \mathrm{mV}$ ), the molecule's whereabouts were less precise. For the case of $\mathrm{Fe}(\mathrm{CO})_{2}$ and $\mathrm{FeCO}$, the tip had difficulty picking up the $\mathrm{CO}$ molecule, even at $1 \mathrm{~V}$ and $100 \mathrm{nA}$.

According to the researchers, this study demonstrates the utility and versatility of the STM. In addition, atomic-scale manipulation of molecules using the STM can provide a new means of nanofabrication.

JUNE LAU

\section{Accelerated Aging of Concrete and Triaxial Test Provide Insight for Long-Term Safety of Nuclear-Storage Containers}

At a meeting of the American Society of Civil Engineers held in May in Austin, Texas, Franz-Josef Ulm of the Massachusetts Institute of Technology (MIT) presented the work of his team on determining the long-term safety of concrete for holding nuclear waste. The current laboratory test can predict aging to about 300 years. While this accelerates concrete aging by a factor of 3 over what other researchers have achieved, Ulm, the Gilbert T. Winslow Career Development Associate Professor of civil and environmental engineering, is confident that the work can be further extrapolated to over 1,000 years.

Concrete weakens over time when water leaches calcium from the material, and calcium is what gives concrete its strength. To accelerate the leaching process, the researchers from MIT and the Commissariat à l'Energie Atomique in France replaced the water with a highly concentrated solution of ammonium nitrate, which caused the calcium to leach at a much higher rate. They coupled this with an oscillating table that ensured an even concentration of solution around each sample.
To expose the weathered materials to stress, the team placed samples into a triaxial high-pressure steel chamber that applied pressures up to $10 \mathrm{MPa}$ from all sides. When they applied a shear, or slightly larger stress from one side, slivers of the material slipped apart.

The researchers found a significant loss of frictional performance in the artificially aged cement paste. The leached calcium left large pores that collapsed under the pressure, allowing the material to slip apart.

Ulm said that the microstructure of the leached cement paste, as visualized with an environmental scanning electron microscope, "showed a strong similarity to that of osteoporotic trabecular bones."

\section{Photo-Induced Densification Causes Refractive-Index Modulation in Ge-Doped Silica Fibers}

The photosensitivity effect is a nonlinear optical phenomenon that has been used to describe the alteration of the refractive index of an optical fiber when exposed to ultraviolet (UV) radiation. Two mechanisms have been proposed to explain the effect: the creation of color centers and structural transformations resulting from densification of the optical fiber. While both mechanisms have been observed experimentally, their relative importance in a given optical system has been a subject of much discussion. In the June 15 issue of Optics Letters, A.I. Gusarov of the Faculté Polytechnique de Mons in Belgium and D.B. Doyle of the European Space Research and Technology Center in The Netherlands have come down firmly on the side of UV-induced densification in the Ge-doped silica fiber system.

Observing that the effect of density variation on the refractive index results from a combination of inelastic structural transformations and photoelastic transformations, the researchers first performed analytical calculations to model the stress distribution, resulting from inscription of a fiber grating, in an optical fiber. They then compared the model with experimental measurements to determine the contribution of densification to the changes in refractive index. By scanning a 3- $\mu \mathrm{m}$-diameter laser probe across the fiber to measure stress-induced birefringence parallel and orthogonal to the fiber axis, they obtained axial stress values averaged over the grating period. Experimental values of $(0.8 \pm 0.2) \times 10^{-11} \mathrm{~m}^{2} \mathrm{~N}^{-1}$ compare favorably with the calculated value of $0.96 \times 10^{-11} \mathrm{~m}^{2} \mathrm{~N}^{-1}$. The slightly higher computed value was attributed to the saturation effect. The experimentally induced axial stress of $124 \mathrm{MPa}$ corresponds to a mean densification of $0.82 \%$, yielding a calculated mean value of $0.99 \times 10^{-3}$ for the index-modulation amplitude versus a measured value of $0.96 \times 10^{-3}$. The researchers conclude that this correlation clearly demonstrates that density changes account for the majority of the photosensitivity effect in the Gedoped silica system, with color-center creation having little or no contribution.

TIM PALUCKA

\section{Elimination of Secondary Nucleation and Grain Coarsening May be Key to Controlled Thin- Film Morphologies}

Controlling the morphology of molecular thin films on substrates is a key factor in determining the interfacial properties of the films and their possible technological applications. The currently preferred epitaxial growth of self-organizing molecules on crystal surfaces has some drawbacks: Mosaics of domains can form, and growth patterns can change from layered, twodimensional structures to granular, threedimensional ones with thickness. Such limitations have been attributed by various investigators to grain coarsening, Ostwald ripening, and secondary nucleation. In an article published in the June 15 issue of Physical Review B, researchers from the Consiglio Nazionale delle RichercheIstituto di Spectroscopia Molecolare in Bologna, Italy, and of the Universitá della Calabria have reported the controlled growth of correlated droplet patterns of mesoscopic (100-1000 nm) dimension and narrow size distribution.

Thin films of the polar conjugated molecule tris(8-hydroxyquinoline) aluminum III $\left(\mathrm{Alq}_{3}\right)$ were grown onto passivated $\mathrm{Si}(100)$ crystal surfaces by high-vacuum sublimation. The substrate temperature was varied between $30^{\circ} \mathrm{C}$ and $150^{\circ} \mathrm{C}$ at a constant deposition rate; the thickness and morphology of the films were determined using scanning force microscopy.

Time-evolution studies of the deposition showed that the number of droplets per unit area is independent of time and therefore coverage, but is strongly dependent on the substrate temperature. This indicates the absence of secondary nucleation and coarsening phenomena. The investigators explain the results using the Capture Zone (CZ) model, in which a Voronoi mosaic forms, based on the initial distribution of nuclei on the substrate. The nuclei grow only by incorporating (that is, capturing) impinging molecules-since coarsening phenomena are absent-so the $\mathrm{CZ}$ mosaic is invariant. Good correlation 